\title{
Çocuk alçısı, askılı alçı, humerus cisim kırıklarında alçılama teknikleri
}

\section{Pediatric casts, hanging cast, casting and bracing techniques in humeral shaft fractures}

\author{
Ahmet Fırat, Ali Şahin, Şahin Çepni
}

Atatürk Eğitim ve Araştırma Hastanesi, Ankara

\begin{abstract}
Ortopedik uygulamada alçılar, travmatik yaralanmalar ve çeşitli kas-iskelet sistemi hastalıklarında rutin olarak kullanılmaktadır. Aynı şekilde, çocuk kırıklarında da alçılama sıklıkla kullanılan bir yaklaşımdır. Deplase olmayan kırıkların hareketsiz hale getirilmesi, deplase kırıkların deplasmanının azaltılması ve ameliyat ile tedavi edilen kırıkların korunması için alçılama yapılabilir. Bu yazıda, çocuk alçısının temel prensip ve uygulamalarından bahsedilmiştir. Humerus cisim kırıkları, tüm kırıkların \%1'ni oluşturur. Humerus cisim kıııları genelde basit düşme, trafik kazaları ve spor yaralanmaları sonucu oluşur. Bu kırıkların konservatif yöntemler ile tedavisinde, yüksek oranda kaynama ve iyi fonksiyonel sonuçlar alınmaktadır. Bu yazıda askılı alçı, $U$ ateli ve fonksiyonel alçı ve breys uygulama tekniği ve prensiplerinden bahsedilmiştir.
\end{abstract}

Anahtar sözcükler: konservatif tedavi; humerus; cisim kırıkları; çocuk alçısı

\begin{abstract}
Casts are widely used for traumatic injuries and various musculoskeletal disorders in orthopaedic practice. It is also used for pediatric fractures usually. Casts can be applied to provide immobilization for nondisplaced fractures, reduce the displacement in fractures, and protect the operated fracture. In this review, the fundamental principles and applications of pediatric casts are discussed. Humeral shaft fractures consist $1 \%$ of all fractures. These fractures occur in commonplace falls, traffic accidents, and sports injuries. Good and excellent fracture healing, and satisfactory functional results are reported in the conservative treatment of humeral shaft fractures. In this review, the technique and principles of hanging cast, $U$ splint, and functional brace are discussed.
\end{abstract}

Key words: conservative treatment; humerus; shaft fractures; pediatric cast

\section{ÇOCUK ALÇISI}

Ortopedik uygulamada alçılar, travmatik yaralanmalar ve çeşitli kas-iskelet sistemi hastalıklarında rutin olarak kullanılmaktadır (Şekil 1). Aynı şekilde, çocuk kırıklarında da alçılama sıklıkla kullanılan bir yaklaşımdır. Deplase olmayan kırıkların hareketsiz hale getirilmesi, deplase kırıkların deplasmanının azaltılması ve ameliyat ile tedavi edilen kırıkların korunması için alçılama yapılabilir. Alçılama işlemi yaygın kullanılan bir yöntem olmasına rağmen, özellikle çocuk kırıklarının cerrahi tedavi yöntemlerinin ilerlemesi ile birlikte, birçok ortopedik eğitim programında alçılamanın teknik ayrıntıları üzerinde fazla durulmamaktadır. Bununla birlikte, alçılama ortopedide temel tedavi yöntemlerinden biri olarak kullanılmaya devam etmektedir. Ortopedi pratiğinde, farklı eğitim almış sağlık çalışanları (hekimler, alçı teknisyenleri, hemşireler, ortezprotez mezunları) alçılama yapıyor olmakla birlikte, alçılama işleminin riskleri olduğu unutulmamalıdır. Kırıkların tedavisinde, uygun şekilde yapılan bir alçı tedavisinin maliyeti cerrahi tedavi maliyetinden önemli oranda daha düşük olarak bulunmuştur. ${ }^{[1]}$

Alçı uygulaması öncesinde ilk verilmesi gereken kararlardan biri, alçının materyalidir. Konvansiyonel alçı ve fiberglas (fiberglass) seçeneklerinin her birinin kendine göre avantaj ve dezavantajları vardır. Konvansiyonel alçı, uygulama esnasında diğer seçeneğe göre daha iyi şekillendirilebilir. İyi oturtulmuş bir alçı, kırık redüksiyonunun korunmasında önemli bir avantaj sağlamaktadır. Suya karşı direncinin zayıf olması, daha düşük sağlamlık ve ağırlığının fazla olması, önemli dezavantajlarıdır. Çocuklarda yapılan alçılamalarda fiberglas alçılar ilk tercih olmaya başlamıştır. Daha hafif olması ve daha az yer kaplaması nedeniyle, ortalama 4-6 hafta süren çocuk alçılarında hekimler tarafından daha çok tercih edilmektedir. ${ }^{[2]}$

- Illetişim adresi: Doç. Dr. Ahmet Fırat, Atatürk Eğitim ve Araştırma Hastanesi, Bilkent Yolu, 06800, Bilkent, Çankaya, Ankara Tel: 0532 - 2304750 e-posta: ahmetfirat24@yahoo.com

- Geliş tarihi: 1 Ağustos 2018 Kabul tarihi: 1 Ağustos 2018 


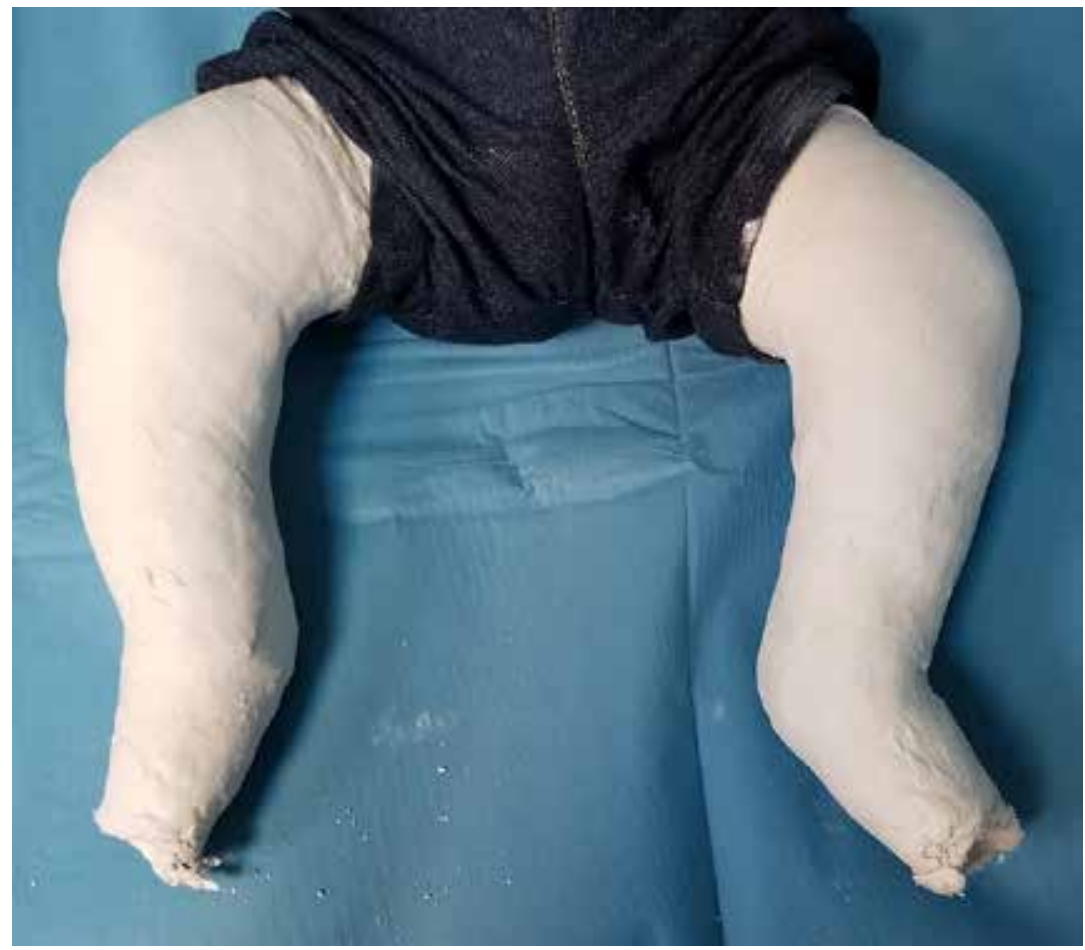

Şekil 1. Pes ekinovarus tedavisinde alçı uygulaması.

Alçı uygulamasından önce, pamuk sargı, sentetik ve suya dayanaklı destek materyalleri kullanılmaktadır. Yapılan bir çalışmada, pamuk destek materyalinin uzun kol alçıda basıncı en iyi azalttığı bildirilmiş ve akut kırıklarda pamuk kullanılması tavsiye edilmiştir. ${ }^{[3]}$ Ayrıca, pamuk alçının daha iyi şekillendirilebilmesine olanak vermektedir.

Alçı uygulamasında sonucu etkileyen birçok faktör mevcuttur. Kullanılan alçı materyalinin yanı sıra alçı destek materyalinin tipi ve miktarı, alçı çorabı kullanımı, alçının en son şekli, alçı sarmanın metodu önemli etkenlerdir. Alçı uygulamasının temel prensiplerinden biri, alçının kırık paterninin redüksiyonuna uygun bir şekilde biçimlendirilmesidir. Küçük bir alana uygulanan aşırı basınç, doku perfüzyonunu bozararak bası ülserlerine neden olabilir. Alçı uygulaması sırasında, alçıya şekil veren elin pozisyonu sabit bir noktada olmamalıdır. Alçıda katlanmaların ve sivri uçların oluşması, basınç noktalarına neden olabileceğinden, önlenmelidir. Özellikle fiberglas alçıların uygulanması esnasında ilk katın uygun şekilde sarılması, alçının çocuğun ekstremitesine oturmasında önemlidir. Alçıya şekil verirken eğer ilk kat gevşek bir şekilde sarılmış ise, alçının kaymasına ve sonuç olarak istenen alçı şeklinin oluşturulamamasına neden olur. ilk katın çok sıkı sarılması ise yumuşak doku hasarı ve dolaşım problemlerine yol açabilir. İdeal uygulama, alçının kendi ağırlığıyla ve üzerine kuvvet uygulamadan sarılmasıdır. Bu teknik yeterli sıkılığı sağlar.

Distal radius ve ulna kırıklarının tedavisinde alçı indeksinin hesaplanması, takip esnasındaki kırığın deplase olma riskini ortaya koyabilir. ${ }^{[4,5]}$ Alçı indeksi ölçümü, direkt grafilerden kırık seviyesinde yapılır ve amaç sagittal-koronal genişlik oranının 0,8 ve daha az olmasının sağlanmasıdır; $0,8^{\prime}$ in altındaki oranlarda deplasman oluşma riski \%5 iken, daha fazla olduğu durumlarda \%26'ya kadar çıkabilir. Radius ve ulna distal kırıklarının tedavisinde esas deforme edici güç olan brakiyoradyalisin gücünü dengelemek amacı ile el bileğine ulnar deviyasyon verilmesi önerilmektedir. Ulnar deviyasyon yapılan olgularda sonuçların daha başarılı olduğu bulunmuştur. ${ }^{[6]}$

Pelvipedal alçı pelvis ve femur immobilizasyonu gerektiren küçük çocuklarda, femur kırığı, proksimal femur osteotomisi veya asetabular osteotomiler, septik artrit ve gelişimsel kalça displazisi gibi çeşitli durumlarda sıklıkla kullanılan bir tedavi yöntemidir. Bu durumların başarılı tedavisi, pelvipedal alçının fiziksel bütünlüğüne ve uzun süreli alçı uygulamasına bağIı gelişebilecek morbiditelere bağlıdır. Pelvipedal alçı 
kullanımı bildiren yayınların çoğu, 1981 yııında Kumar tarafından tanımlanan tekniği anlatır. ${ }^{[7]}$ Pelvipedal alçının özellikle femoral pelvik bileşkeden kırılması yaygın görülen bir problemdir ve bu nedenle bazı yazarlar, alçının alt ekstremite komponentlerini birbirine bağlayan ara bağlantı çubukları da olmak üzere dayanıklılığı geliştirmek için standart teknikte bazı değişiklikler önerdiler. ${ }^{[8]}$ Pelvipedal alçı, gövde ve bilateral uzun bacak alçı şeklinde, tek taraf uzun bacak ve diğer taraf yarım (diz eklem hareketi korunacak şekilde) ya da tek taraf uzun bacak alçı diğer taraf serbest olacak şekilde uygulanabilir.

Amerikan Ortopedik Cerrahi Akademisi'nin en son kılavuzunda, beş aydan altı yaşa kadar olan çocuklarda femur diyafiz kırıkları için 20 mm'lik kısalığa kadar birincil tedavi pelvipedal alçı olarak önerilmektedir. ${ }^{\left[{ }^{[}\right]}$ Pelvipedal alçı ile immobilizasyon tedavisinin küçük çocuklarda femur kırıkları için basit, güvenli ve düşük maliyetli bir tedavi olduğu gösterilmiştir. ${ }^{[10,11]}$

Alçıya bağlı komplikasyonlar; alçının uygulanması sırasında, alçı immobilizasyonu boyunca veya alçının uzaklaştırılması sırasında oluşabilir. ${ }^{[12-14]}$ Alçılamanın komplikasyonlarını bildiren, tarihi değeri olan ve yeni basılmış birçok çalışma literatürde mevcuttur. Bu çalışmaların birçoğu, pelvipedal alçılama ile uzun ve kısa kol alçılar üzerine yapılmıştır. ${ }^{[3,4,15-17]}$ Bildirilen komplikasyonlar, basit cilt yaralanmalarından kompartman sendromuna kadar farklı patolojileri kapsamaktadır. Yanlış veya düzensiz şekilde uygulanan alçılar bası yaralarına neden olabilir; gevşek sarılan alçı keskin kenarlara ve cilt irritasyonuna yol açabilir. Sıkı sarılan alçılar bası yaralarına veya kompartman sendromuna yol açabilir. Alçı suyunun sıcak olması ise termal yaralanmalara yol açabilir. Uygun yapılmayan alçılama hastaların sıklıkla acile başvurmasına neden olmaktadır. Yapılan bir çalışma, alçıya bağlı problemlerle acile başvuruların \%29'unun ıslak alçı, \%10'unun hasar görmüş alçı, \%23'ünün sıkı alçı, \%13'ünün gevşek alçı ve \%10'unun yeni ortaya çıkan ağrı nedeni ile olduğunu göstermiştir. ${ }^{[1]}$

Alçı uygulamasına bağlı yanıklar, literatürde birçok çalışmada bildirilmiştir. ${ }^{[12,18]}$ Alçının kuruması, ısı açığa çıkaran bir reaksiyondur. Alçının ıslatıldığı suyun sıcaklığının özellikle $50^{\circ} C^{\prime} ı n$ üstünde olduğu durumlarda ve aşıı kalın alçının çıkarılması sırasında, termal hasar riski belirgin bir şekilde artmaktadır.

Alçının ıslanması, ciltte maserasyon, enfeksiyon ve alçı bütünlüğünün bozulması gibi çeşitli komplikasyonlara neden olabilir. Ailenin ve hastanın alçının kuru tutulması konusunda eğitilmesi, ıslak alçı komplikasyonlarının önlenmesinde en önemli yöntemdir. Bunun yanı sıra, ticari olarak satılan alçı koruyucuları veya su geçirmez koruyucular da yararlı olabilir.
Cilt kompliklasyonları, ciltte önemsiz soyulmalardan debridman gerektiren basınç ülserlerine kadar geniş klinik durumları kapsamaktadır. Üst ve alt ekstremite alçıları ile tedavi edilen çocuklarda cilt komplikasyonlarının oranı tam olarak bilinmemektedir. Pelvipedal alçılar ile tedavi edilen çocuklarda ise cilt komplikasyonları oranları çeşitli çalışmalarda \%15 ile \%38 arasında bulunmuştur.[13,19,20] Cilt komplikasyonlarının oluşmasında en sık neden, alçı destek materyalinin (alçı pamuğunun) yanlış uygulanmasıdır. Basınç ülserlerinin önlenmesinde, ekstremitelerdeki femur kondilleri, fibula başı ve topuk gibi çıkıntılı kemik noktalarında özen gösterilmesi önemlidir. Topuk gibi yüksek basınca maruz kalacak noktalara ekstra destek materyali uygulanması yararlıdır.

Travmadan hemen sonra yapılan kapalı redüksiyon ve alçılama sonrası ekstremitenin şişmesi yaygındır. Bu şişme, ekstremite için basınç artışı ve nörovasküler komplikasyonlara yol açabilir. Bu şişmeye bağlı gelişebilecek komplikasyonları önlemenin yolu alçının gevşetilmesidir. Alçı, alçı motoru kullanılarak longitudinal ve düz bir şekilde ekstremitenin uzun aksına paralel olacak şekilde kesilir. Alçının gevşetilmesi sırasında alttaki pamuğun da gevşetilmesinin komplikasyonları önlemede çok önemli olduğu gösterilmiştir. ${ }^{[21,22]}$

Titreşimli alçı motoru ile alçının gevşetilmesi veya çıkarılması işlemi tamamen komplikasyonsuz bir işlem değildir. Alçı motorunun kullanılması ve komplikasyonları ile ilgili literatürde pek çok çalışma mevcuttur. ${ }^{[15,16,23,24]}$ Osilasyon mekanizması ile çalışan alçı motorlarının cildi kesmeyeceği, sadece alçıyı keseği belirtilse de, abrazyonlara ve yanıklara neden olabileceği bilinmelidir. Shuler ve ark. ${ }^{[16]}$ yapmış oldukları çalışmada, kalın destek materyali kullanılmamasının alçı kesme motorunun ısınmasını önlemede yararlı olduğunu bildirmişlerdir. Killian ve ark. ${ }^{[15]}$ ise alçı motor bıçağının körelmesinin, fazla kalın alçıların ve alçı çıkarma işlemini gerçekleştiren teknisyenin deneyimsizliğinin yanıklara neden olduğunu belirtmişlerdir. Birçok makalede, alçı testeresine bağlı komplikasyonların gelişmesinde alçı çıkarma işlemini uygulayan kişinin deneyiminin önemli rol oynadığı ve tecrübesiz kişiler tarafından uygulanan işlemin çocuğa önemli zararlar verebileceği belirtilmiştir. ${ }^{[15,23]} \mathrm{Alçı}$ uygulaması sırasında alçı koruyucu materyal üzerine yerleştirilen bir malzeme olan testere koruyucu bant (Saw Stop ${ }^{\odot}$ ) kullanılması, alçı kesme motoru yaralanmalarını önlemekte etkili olabilir.

Şimdiye kadar bahsedilen konular kadar önemli olan bir nokta da, hastalar ve ebeveynlerinin alçının kullanımı konusunda ayrıntılı bir şekilde bilgilendirilmesidir. Alçı tedavisinin, ortopedi uzmanları için sık kullanılan rutin bir prosedür olmasına rağmen, hasta 
ve hasta yakınları için hayatlarına giren yeni bir unsur olduğu unutulmamalıdır. Yapılması ve yapılmaması gereken şeylerin üstünde durulması, komplikasyonların önlenmesi açısından önemlidir. Dipaula ve ark. ${ }^{[25]}$ yapmış oldukları ileriye dönük bir çalışmada, alçıları değiştirilmek zorunda kalınan hastalarda bunun en sık nedeninin alçının uygulama tekniği değil, hasta ve hasta yakınlarının alçı bakımına özen göstermemeleri ile alakalı olduğunu bulmuşlardır. Her alçı uygulaması sonrasında aileye ve çocuğa alçı bakımı ile ilgili tüm ayrıntılar dikkatlice anlatılmalıdır. Alçının ıslanmaktan nasıl korunacağı, alçının içine herhangi bir yabancı materyal girmesinin engellenmesi, kaşıntı gibi semptomlar ile nasıl başa çıkılacağı konusunda herkes bilgilendirilmelidir. Hastalara, alçı bakımını ve komplikasyonlarını ayrıntılı bir şekilde açıklayan broşürler verilmelidir.

\section{HUMERUS CISIM KIRIKLARINDA ALÇILAMA}

Humerus cisim kırıkları, tüm kırıkların \%1'ni oluşturmaktadır. ${ }^{[26]}$ Humerus cisim kırıkları genelde basit düşme, trafik kazaları ve spor yaralanmaları sonucu oluşur. Bu kırıkların konservatif yöntemler ile tedavisinde, yüksek oranda kaynama ve iyi fonksiyonel sonuçlar alınmaktadır. Konservatif tedavi nerdeyse tüm hastalarda ilk seçenek olmasına rağmen, açık kırıklar, çoklu travmalı hastalar, yüzen dirsek, bilateral kırıklar, patolojik kırıklar, damar yaralanmalı hastalar ve kabul edilebilir redüksiyon pozisyonu korunamayan hastalarda cerrahi tedavi tercih edilebilir. Cerrahi olmayan tedavi yöntemleri; kaynamamanın nadir oluşu, iyileşme süresinin kısalması ve enfeksiyonun sık olmaması gibi avantajlarından dolayı tercih edilmektedir. ${ }^{[27]}$ Sarmiento ve ark., konservatif tedavi edilen 922 hasta üzerinde yapılan çalışmada, kaynama oranını \%97 olarak bildirmiştir. ${ }^{[27]}$ Zagarski ve ark., 233 hasta üzerinde yapılan çalışmada, \%98 kaynama oranı ve \%95 hastada da mükemmel fonksiyonel sonuç bildirmiş̧tir. ${ }^{[28]}$ Humerus cisim kırıklarının konservatif tedavisinde, askılı alçı, "U" alçı ve fonksiyonel breys, konservatif tedavi yöntemleri olarak uygulanmaktadır.

\section{ASIKILI ALÇI (HANGING CAST)}

ilk olarak 1933 yılında Caldwell tarafından tanımlanmıştır. ${ }^{[29]} \mathrm{Bu}$ alçının özelliği; alçının ağırlığı ile yaklaşık $1-1,5 \mathrm{~kg}$ traksiyon yapılıp kırı̆ı̆ın redüksiyonunun sağlanmasıdır. ${ }^{[30]} \mathrm{Bu}$ alçının etkili olması için hastanın devamlı dik veya yarı oturur pozisyonda olması gerekir. Askılı alçı tedavisinin en başarılı olduğu kırıklar; humerusun diyafizinin orta bölgesindeki deplase, oblik ve spiral kırıklardır. Transvers kırıklarda; distraksiyona bağlı kaynama problemi yaşanabileceğinden dolayı pek tavsiye edilmemektedir. Eğer

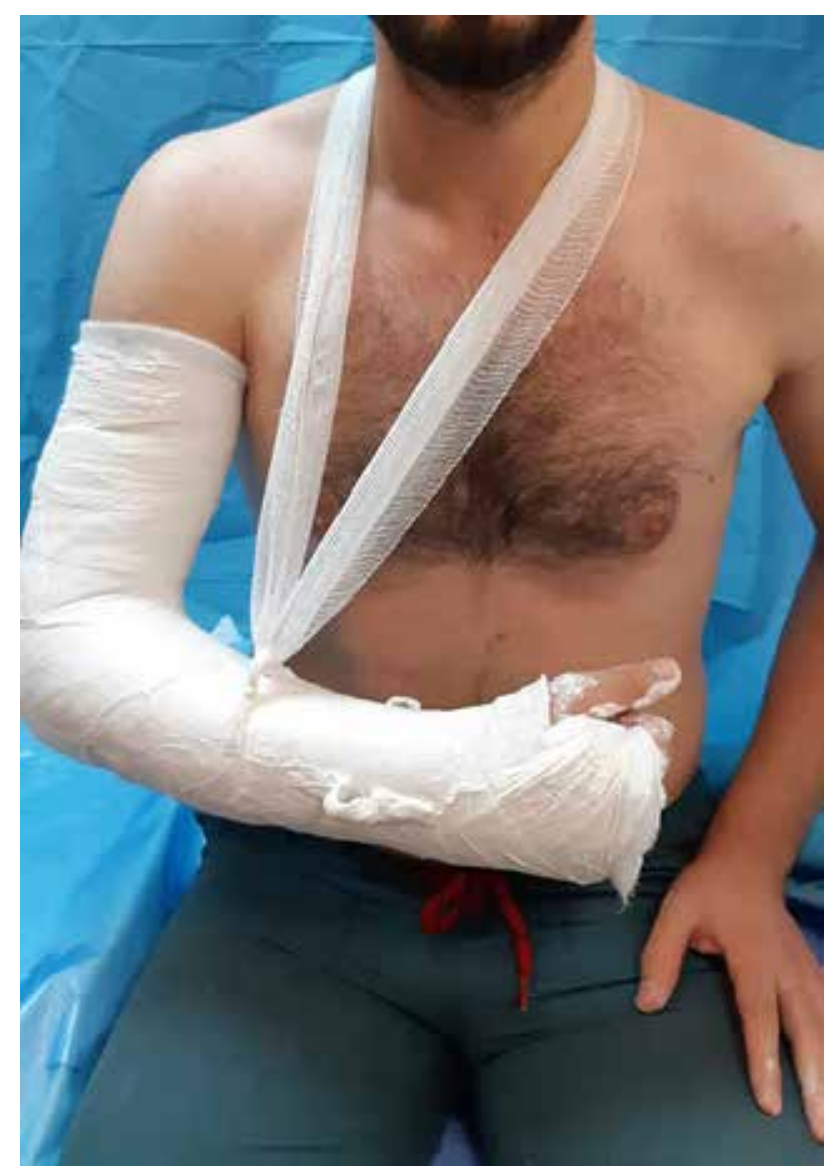

Şekil 2. Askılı alçı (hanging cast).

distraksiyon fazla olursa kaynama gecikmesi ve psödoartroz gelişebilir. ${ }^{[31]}$

Askılı alçı tedavisi dikkat ve ayrıntı gerektirir. ${ }^{[29,32]}$ Alçı, distraksiyona engel olacak şekilde hafif yapılmalı, dirsek $90^{\circ}$ fleksiyonda ve önkol nötral rotasyonda olmalıdır; kırık hattının en az $2 \mathrm{~cm}$ proksimaline kadar yapılmalıdır. Üç adet halka önkol distaline dorsal, nötral ve volar pozisyonlarda uygulanır (Şekil 2). Kırık bölgesindeki angülasyon anteriora bakıyorsa nötraldeki halka kullanılarak kol kaldırılır ve boyun askısı kısaltılır; mediyale angülasyon varsa volar halka kullanılarak düzeltilir; laterale angülasyon varsa dorsaldeki halka kullanılarak düzeltilir. ${ }^{[33]}$

Bu yöntemde, omuz ve dirsek sertliği, boyun ağrıları gibi problemler görülebilir. Ağrıya tolerans olduğu sürece pasif omuz egzersizlerine başlanır. Rehabilitasyona özen gösterilmezse omuzda kalıcı hareket kısıtlılığı gelişebilir. İzometrik egzersizlere, hastanın şikayetleri azaldığında başlanmalıdır. Önce pasif daha sonra aktif ekstansiyon-fleksiyon hareketleri yaptırılır. ${ }^{[29]}$ 

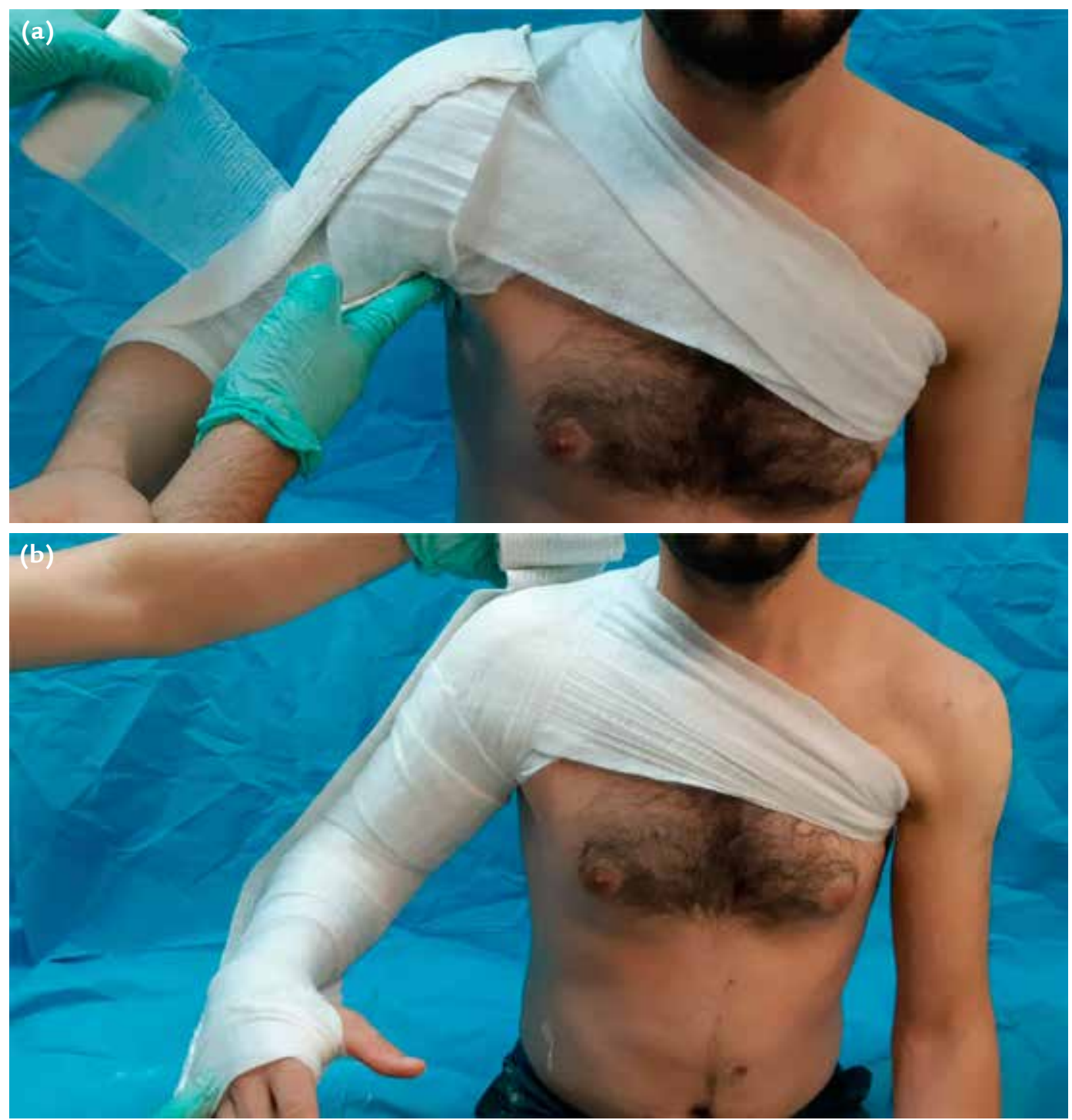

Şekil 3. a, b. Humerusa U-ateli uygulaması (a). U-ateli uygulamasında uzun kol ateli ile önkolun desteklenmesi (b).

Bu tedavi literatürde De Morgues ${ }^{[34]}$ ve Babin'in ${ }^{[35]}$ çalışmaları ile birlikte klasik bir yöntem haline gelmiş, ancak sonradan popülaritesi azalmıştır. Yapılan çok merkezli bir çalışmada, 2003'te Fransa'da kullanımı \%50 düzeyinde bildirilmiştir. ${ }^{[36]}$ Bu yöntem ile kaynama oranı \%96'nın üzerinde bildirilmiştir. ${ }^{[29,32]}$

\section{U-ATELi}

Minimal kısalıkla birlikte olan humerus diyafizinin akut kırıklarında kullanılır. U-ateli uygulamasında, humerus için uygun pozisyon verildikten sonra kol üzerine pamuk sarılıp dirsek $90^{\circ}$ fleksiyona alınır (Şekil 3a).
Atel uygun uzunlukta, yaklaşık $10 \mathrm{~cm}$ genişliğinde ve 8-10 katı geçmeyecek şekilde hazırlanır. Atelin uçları omzu kavrayacak şekilde omuz üzerine doğru getirilir. Daha sonra, önkolu nötral pozisyonda tutacak şekilde, humerusun posteriorundan başlayan uzun kol ateli uygulanır (Şekil 3b). Humerus bölgesi sargısının sıkı olmasına dikkat edilmelidir. U-ateli sonrası hastalar sık sık röntgen kontrolüne çağrılmalıdır. Hasta, omuz, dirsek, el bileği ve el egzersizleri konusunda eğitilmelidir. Bu yöntemin dezavantajı olarak; dirsekte ekstansiyon kısıtlılı̆ı, aksiller bölgede irritasyon, omuzda hareket kısıtlılığı ve hastalar tarafından iyi tolere edilememesi sayılabilir. ${ }^{[12]}$ Steward ve Hundley, U-ateli ile tedavi 
ettikleri hastalarda ortalama 10 haftada kaynama bildirmişler ve kaynama oranını \%94 olarak saptamışlardır. ${ }^{[32]}$ Aynacı ve ark. ortalama 3,6 ayda, \%91,2 kaynama elde etmişlerdir. ${ }^{[37]}$

\section{FONKSIYONEL BREYS}

ilk olarak 1977 yilında Sarmiento tarafindan tanımlanmıştır. ${ }^{[29,38]}$ Kırığın çevresindeki yumuşak dokulara kompresyon yaparak redüksiyonu sağlayan bir ortezdir. ${ }^{[29]} \mathrm{Bu}$ ortezin kullanımında omuz ve dirseğe egzersiz verilebilmesi, bu tedavi yöntemini diğerlerinden üstün kılmaktadır. Fonksiyonel breys, humerus diyafız kırıklarının konservatif tedavisinde en çok kullanılan yöntemdir. ${ }^{[32,39]}$ Primer olarak kullanıldığı gibi, askılı alçı ve U-ateli kullanımından 1-2 hafta sonra da kullanılabilir.

Humerus şaft kırıklarının breys ile tedavisinde ideal endikasyonlar; kooperasyonu iyi ve şişman olmayan hastalarda kapalı spiral veya oblik, proksimal veya orta $1 / 3$ izole humerus şaft kırıklarıdır. Parçalı, segmenter, distal $1 / 3$ ve açık kırıklar, ortopedistin tecrübesine göre rölatif kontrendikasyonları oluşturmaktadır. Kooperasyonu iyi olmayan veya mobilize olamayan hastalar ile brakiyal arter lezyonu, yumuşak doku interpozisyonu veya ciddi yumuşak doku hasarının eşlik ettiği kırıklar, patolojik veya segmenter kemik kaybı olan kırıklar, breys tedavisinin mutlak kontrendike, cerrahi tedavinin endike olduğu kırıklardır.

Breys, hastaya göre imal edilmelidir (custom made). Hasta oturtulup her iki epikondilden düşey doğrultuda traksiyon yapılırken, üç nokta prensibine uygun olarak, üstte akromiyonun distali, altta ise her iki epikondilin hemen proksimalinden breys yapılır ve hastaya uygulanır. ${ }^{[40]}$ İyi bir sonuç elde etmek için, breys kolu sıkı bir şekilde sarmalıdır (Şekil 4). ${ }^{[41]}$ Breys bazı uygulamalarda ilk birkaç hafta ödem kontrolünü sağlayana kadar, bu birkaç hafta için alçıdan yapılabilir. Kola alçı çorabı geçirilerek üzerine alçı sarılır ve el ile şekillendirilerek redüksiyon yapılır. Sonrasında termoplastik veya poliüretan malzemeden hastanın ölçüsü alınarak custom made breyse geçilir. Breys, sıkılığının ayarlanabilmesi için bir kanal ve ayarlanabilir bantlar içermelidir. Radyolojik kontrolle gerekli düzeltmeler yapılır. Breys uygulandıktan hemen sonra, önce pasif ve sonra aktif yardımlı daha sonra aktif omuz ve dirsek egzersizlerine başlanabilir. ${ }^{[40]}$ Breys primer olarak uygulanmışsa, hasta daha sonraki günlerde kol ve önkoldaki ödem miktarı ile ekstremitenin nörovasküler durumu açısından tekrar değerlendirilmelidir. Breys kullanımındaki temel amaç, erken harekete başlayarak, gelişecek olan eklem hareket kısıtlılığına engel olmak ve kaslardaki aktivite artışı ile kırık iyileşmesini hızlandırmaktır. ${ }^{[40]}$ Breys kırık sonrası maksimum 8-10 hafta kullanılmalıdır. ${ }^{[42]}$

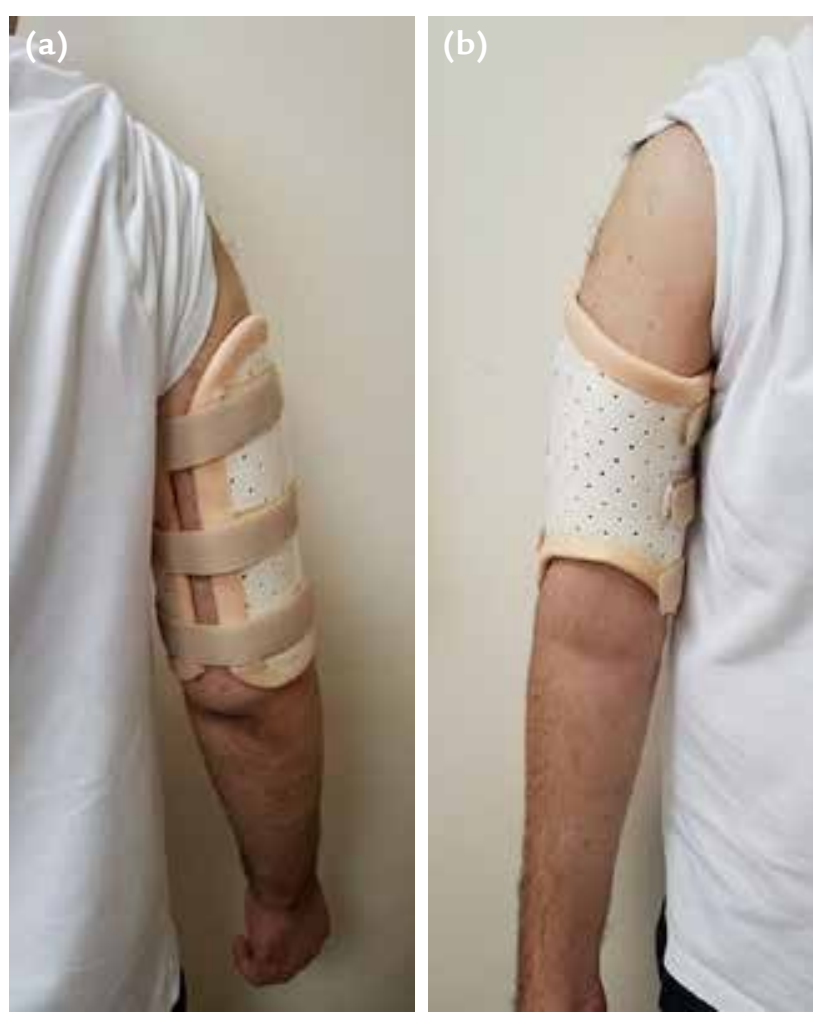

Şekil 4. a, b. Fonksiyonel breys uygulamasının arkadan (a) ve önden (b) görünüşleri.

Sarmiento ve ark. fonksiyonel breys ile tedavi ettikleri 620 hasta üzerinde yapılan çalışmada, kaynamama oranını kapalı kırıklarda \%2, açık kırıklarda \%6 ve hastaların $\% 87^{\prime}$ sinde $16^{\circ}$ 'den az varus açılanma, sadece $\% 2$ hastada $25^{\circ}$ 'den fazla varus açılanma tespit etmişlerdir. ${ }^{[27]}$ Papasoulis ve ark., yapmış oldukları çalışmada kaynama oranını \%94,5 olarak bildirmişlerdir. ${ }^{[43]}$ Shields ve ark., cerrahi tedavi ile konservatif tedavi yöntemleri arasında fonksiyonel sonuç açısından istatistiksel olarak anlamlı fark bulmamışlardır. ${ }^{[44]}$ Koch ve ark., fonksiyonel breys ile tedavi ettikleri 67 hastada \%95 başarılı sonuç almışlardır. ${ }^{[45]}$

Denard ve ark., cerrahi tedavi ettikleri 150 hasta ve konservatif tedavi ettikleri 63 hasta ile yapmış oldukları çalışmada, kaynamama oranını cerrahi yaptıkları hastalarda $\% 8,7$ konservatif tedavi ettiklerinde $\% 20,6$, malunion oranlarını ise cerrahide \%1,3 konservatifte $\% 12,7$ olarak bildirmişlerdir. Radyal sinir arazı oranlarını ise; cerrahide $\% 2,7$, konservatif grupta $\% 9,5$ olarak bildirmişlerdir. ${ }^{[41]}$ Matsunaga ve ark., yapmış oldukları çalışmada kaynamama oranını, cerrahi yaptıkları hastalarda \%0, fonksiyonel breys ile konservatif tedavi ettikleri hastalarda \%15 olarak bildirmişlerdir. ${ }^{[46]}$ 
Literatürde, proksimal 1/3 cisim kırıklarının distal 2/3 kırıklarına oranla daha yüksek kaynamama oranına sahip olduğu birçok çalışmada bildirilmiştir. ${ }^{[47-49]}$ Zuckherman ve Koval, humerus proksimal ve distal 1/3 cisim kırıklarının kaynama gecikmesi ve kaynamama komplikasyonları açısından, orta 1/3 kırıklara nazaran daha riskli kırıklar olduğunu belirtmişlerdir. ${ }^{[42]}$ Ali ve ark.'nın fonksiyonel breys ile tedavi ettikleri 138 hasta üzerinde yapılan çalışmasında, kaynama oranları $\% 83$ olarak bildirilmiş olup, proksimal üçte birlik kısımda olan kırıkların kaynama oranının diğer bölgelere göre daha düşük olduğu belirtilmiştir. ${ }^{[47]}$ Başka bir çalışma$\mathrm{da}$, proksimal ve transvers kırıklarda non-union oranları \%20-50 arasında bulunmuştur. ${ }^{[38,49]}$ Sarmiento ve ark., fonksiyonel breys ile tedavi ettikleri distal $1 / 3$ kırıklarda kaynama oranını \%96 olarak bildirmişlerdir. ${ }^{[27]}$ Pehlivan ve ark., fonksiyonel breys ile tedavi ettikleri izole kapalı 21 distal 1/3 humerus cisim kırı̆ğın kaynama oranını \%100, ortalama kaynama süresini 12 hafta olarak bildirmişlerdir. ${ }^{[50]}$

Literatürde, transvers kırıklarda (AO Tip 3) non-union oranlarının daha yüksek olduğu bildirilmiştir. ${ }^{[27,45,51]}$ Ring ve ark. transvers kırıklarda kaynamama oranının oblik/spiral kırıklara göre daha yüksek olduğunu bildirmelerine rağmen ${ }^{[52]}$, Matsunaga ve ark. kırık paterni ile kaynama oranları arasında bir korelasyon olmadığını bildirmişlerdir. ${ }^{[46]}$

Koch ve ark., fonksiyonel breys ile tedavi ettikleri 67 hastanın dokuzunda kaynamama tespit etmiş ve bu dokuz hastanın beşinin de transvers kırığı olan hastalar olduğunu bildirmişlerdir. ${ }^{[45]}$ Ekholm ve ark., yapmış oldukları çalışmada, kaynamama oranını Tip A kırıklarda \%18, Tip B kırıklarda \%4, Tip C kırıklarda \%0 olarak bulmuşlardır. ${ }^{[51]}$ Sarmiento ve ark., transvers kırıklarda ortalama kaynama süresini 12 hafta, oblik kırıklarda ise 10 hafta olarak bildirmişlerdir. ${ }^{[27]}$ Kırık paternlerine göre kaynama süreleri arasındaki farkın nedeni tam olarak belli değildir. ${ }^{[4]}$ Transvers kırıklarda oblik/spiral kırıklara göre daha az kemik temas yüzey alanı olması, muhtemel nedenlerden birisidir. ${ }^{\left[{ }^{[2]}\right.}$

Son çalışmalara göre; $3 \mathrm{~cm}$ 'den az kısalma, $20^{\circ}$ 'den az sagittal plan ve $30^{\circ}$ 'den az koronal plan açısal deformiteler, humerus kırıklarında kabul edilebilir redüksiyon kriterleri sayılmaktadır. ${ }^{[33,54]}$ Zagorski ve ark., $25^{\circ}$ 'ye kadar olan açısal deformitelerin ve $5 \mathrm{~cm}$ 'ye kadar olan kısalığın, koldaki kas kitlesinin fazla olması ve omuz ile dirseğin geniş hareket kabiliyetleri nedeniyle, fonksiyonel ve kozmetik bir sonuç oluşturmayacağını bildirmişlerdir. ${ }^{[28]}$ Shields ve ark., $0-18^{\circ}$ arası sagittal plan deformitelerinin ya da $2-27^{\circ}$ arası koronal plan deformitelerinin, fonksiyonel skor üzerinde etkisi olmadığını bildirmişlerdir. ${ }^{[55]}$ Matsunaga ve ark., yapmış oldukları çalışmada, DASH (Disabilities of the Arm, Shoulder and
Hand) skoru cerrahi grupta fonksiyonel breys ile tedavi ettikleri gruba göre daha yüksek iken, Short Form-36, VAS (visual analog scale) skoru, Constant-Murley skoru arasında anlamlı fark olmadığını bildirmişlerdir. ${ }^{[46]}$ Fırat ve ark.'nın humerus cisim kırıklarının tedavisinde omuz dirsek sonuçlarını değerlendirdikleri çalışmada, fonksiyonel breys uygulanan grupta cerrahi gruba göre daha iyi sonuçlar elde edilmiştir. ${ }^{[56]}$

Kırık kaynama oranları açısından fonksiyonel breysin diğer kapalı yöntemlere bir üstünlüğü olmamakla beraber, kırık iyileşme hızını arttırması, hasta konforunun yüksek olması, kişisel hijyene olanak sağlaması ve omuz dirsek hareketlerini kısıtlamaması, breys tedavisinin tercih nedenlerini oluşturur.

\section{KAYNAKLAR}

1. Sawyer JR, Ivie CB, Huff AL, Wheeler C, Kelly DM, Beaty $\mathrm{JH}$, Canale ST. Emergency room visits by pediatric fracture patients treated with cast immobilization. J Pediatr Orthop 2010;30(3):248-52. Crossref

2. Halanski M, Noonan KJ. Cast and splint immobilization: complications. J Am Acad Orthop Surg 2008;16(1):30-40. Crossref

3. Roberts A, Shaw KA, Boomsma SE, Cameron CD. Effect of Casting Material on the Cast Pressure After Sequential Cast Splitting. J Pediatr Orthop 2017;37(1):74-7. Crossref

4. Webb GR, Galpin RD, Armstrong DG. Comparison of short and long arm plaster casts for displaced fractures in the distal third of the forearm in children. J Bone Joint Surg Am 2006;88(1):9-17. Crossref

5. Chess DG, Hyndman JC, Leahey JL, Brown DC, Sinclair AM. Short arm plaster cast for distal pediatric forearm fractures. J Pediatr Orthop 1994;14(2):211-3. Crossref

6. Edmonds EW, Capelo RM, Stearns P, Bastrom TP, Wallace CD, Newton PO. Predicting initial treatment failure of fiberglass casts in pediatric distal radius fractures: utility of the second metacarpalradius angle. J Child Orthop 2009;3(5):375-81. Crossref

7. KumarSJ. Hip spica application for the treatment of congenital dislocation of the hip. J Pediatr Orthop 1981;1(1):97-9. Crossref

8. Hosalkar HS, Jones S, Chowdhury M, Chatoo M, Hill RA. Connecting bar for hip spica reinforcement: does it help? J Pediatr Orthop B 2003;12(2):100-2. Crossref

9. Kocher MS, Sink EL, Blasier RD, Luhmann SJ, Mehlman CT, Scher DM, Matheney T, Sanders JO, Watters WC 3rd, Goldberg MJ, Keith MW, Haralson RH 3rd, Turkelson CM, Wies JL, Sluka P, Hitchcock K. Treatment of paediatric diaphyseal femur fractures. J Am Acad Orthop Surg 2009;17(11):718-25. Crossref

10. Anglen J, Choi L. Treatment options in pediatric femoral shaft fractures. J Orthop Trauma 2005;19(10):724-33. Crossref

11. Infante AF Jr, Albert MC, Jennings WB, Lehner JT. Immediate hip spica casting for femur fractures in pediatric patients. A review of 175 patients. Clin Orthop Relat Res 2000;376:10612. Crossref

12. Lavalette R, Pope $M H$, Dickstein $H$. Setting temperatures of plaster casts. The influence of technical variables. J Bone Joint Surg Am 1982;64(6):907-11. Crossref 
13. DiFazio R, Vessey J, Zurakowski D, Hresko MT, Matheney T. Incidence of skin complications and associated charges in children treated with hip spica casts for femur fractures. J Pediatr Orthop 2011;31(1):17-22. Crossref

14. Ansari MZ, Swarup S, Ghani R, Tovey P. Oscillating saw injuries during removal of plaster. Eur J Emerg Med 1998;5(1):37-40 Crossref

15. Killian JT, White $S$, Lenning L. Cast-saw burns: comparison of technique versus material versus saws. J Pediatr Orthop 1999;19(5):683. Crossref

16. Shuler FD, Grisafi FN. Cast-saw burns: evaluation of skin, cast, and blade temperatures generated during cast removal. J Bone Joint Surg Am 2008;90(12):2626-30. Crossref

17. Ferguson J, Nicol RO. Early spica treatment of pediatric femoral shaft fractures. J Pediatr Orthop 2000;20(2):18992. Crossref

18. Gannaway JK, Hunter JR. Thermal effects of casting materials. Clin Orthop Relat Res 1983;(181):191-5. Crossref

19. Illgen R II, Rodgers WB, Hresko MT, Waters PM, Zurakowski $D$, Kasser JR. Femur fractures in children: treatment with early sitting spica casting. J Pediatr Orthop 1998;18(4):481-7. Crossref

20. Podeszwa DA, Mooney JF III, Cramer KE, Mendelow MJ. Comparison of Pavlik harness application and immediate spica casting for femur fractures in infants. J Pediatr Orthop 2004;24:460-2. Crossref

21. Bingold AC. On splitting plasters: a useful analogy. J Bone Joint Surg (British) 1979;61-B(3):294-5. Crossref

22. Younger ASE, Curran P, McQueen MM. Backslabs and plaster casts: which will best accommodate increasing intracompartmental pressures? Injury 1990;21(3):179-81. Crossref

23. Brubacher JW, Karg J, Weinstock P, Bae DS. A Novel Cast Removal Training Simulation to Improve Patient Safety. J Surg Educ 2016;73(1):7-11. Crossref

24. Nielsen DM, Ricketts DM. Where to split plaster casts. Injury 2005;36(5):588-9. Crossref

25. DiPaola MJ, Abzug JM, Pizzutillo PD, Herman MJ. Incidence and etiology of unplanned cast changes for fractures in the pediatric population. J Pediatr Orthop 2014;34(6):643-6. Crossref

26. Ekholm R, Adami J, Tidermark J, Hansson K, Törnkvist $\mathrm{H}$, Ponzer S. Fractures of the shaft of the humerus. an epidemiological study of 401 fractures. J Bone Joint Surg Br 2006;88-B(11):1469-73. Crossref

27. Sarmiento A, Zagorski JB, Zych GA, Latta LL, Capps CA. Functional bracing for the treatment of fractures of the humeral diaphysis. J Bone Joint Surg Am 2000;82(4):478-86. Crossref

28. Zagorski JB, Latta LL, Zych GA, Finnieston AR. Diaphyseal fractures of the humerus. Treatment with prefabricated braces. J Bone Joint Surg Am 1988;70(4):607-10. Crossref

29. Caldwell JA. Treatment of fractures in the Cincinnati General Hospital. Ann Surg 1933;97(2):161-76. Crossref

30. Charles A, Rockwood Jr., David PG, Robert WB, James DH. Rockwood and Green's Fractures in Adults. Lippincott-Raven; 1996. p.197-201

31. Caldwell JA. Treatment of fractures of the shaft of the humerus by hanging cast. Surg Gynecol Obstet 1940;70:421-5.

32. Stewart MJ, Hundley JM. Fractures of the humerus. A comparative study in methods of treatment. J Bone Joint Surg Am 1955;37(4):681-92. Crossref
33. Leyshon RL. Closed treatment of fractures of the proximal humerus. Acta Orthop Scand 1984;55(1):48-51. Crossref

34. de Mourgues G, Fischer LP, Gillet JP, Carret JP. Fractures récentes de la diaphyse humérale [Recent fractures of the humeral diaphysis. Apropos of a continuous series of 200 cases, of which 107 were treated with a hanging cast alone. (Arterial intra-osseous vascularization of the humerus)]. Rev Chir Orthop Reparatrice Appar Mot 1975;61(3):191-207.

35. Babin SR. Les fractures de la diaphyse humérale de l'adulte. Cahiers d'enseignement de la SOFCOT. Paris: Expansion scientifique francaise; 1975. p.91-114.

36. Lefevre C. Fractures diaphysaires de I'humérus chez l'adulte. Rev Chir Orthop Reparatrice Appar Mot 2004;90(Suppl 5):1S27-67. Crossref

37. Aynaci O, Aydin H, Erkut A, Sener M. Treatment of humeral shaft fractures with the use of $U$-splints. Acta Orthop Traumatol Turc 2001;35:232-5.

38. Sarmiento A, Kinman PB, Galvin EG, Schmitt RH, Phillips JG. Functional bracing of the shaft of the humerus. J Bone Joint Surg Am 1977;59(5):596-601. Crossref

39. Lavini F, Renzi Brivio L, Pizzoli A, Giotakis N, Bartolozzi P. Treatment of non-union of the humerus using the Orthofix ${ }^{\circledR}$ external fixator. Injury 2001;32 Suppl 4:35-40. Crossref

40. Karaoğlu A. Humerus diafiz psödoartrozlarında cerrahi tedavi metodlarının karşılaştırılması. ì. Ü. İstanbul Tıp Fakültesi Ortopedi ve Travmatoloji Anabilim Dalı, Uzmanlık Tezi, İstanbul; 2001.

41. Denard A, Richards JE, Obremskey WT, Tucker MC, Floyd M, Herzog GA. Outcome of nonoperative vs operative treatment of humeral shaft fractures: a retrospective study of 213 patients. Orthopedics 2010;33(8). Crossref

42. Zucherman JD Koval KJ. Fractures of the shaft of the humerus. In: Rockwood CA, Green DP, Bucholz RW, Heckman JD, editors. Fractures in Adults, 4th ed. Philadelphia, PA: Lippincott-Raven; 1996. p.1025-53.

43. Papasoulis E, Drosos GI, Ververidis AN, Verettas DA. Functional bracing of humeral shaft fractures. A review of clinical studies. Injury 2010;41(7):e21-7. Crossref

44. Shields E, Sundem L, Childs S, Maceroli M, Humphrey C, Ketz J, Gorczyca JT. Factors predicting patient-reported functional outcome scores after humeral shaft fractures. Injury 2015;46(4):693-8. Crossref

45. Koch PP, Gross DF, Gerber C. The results of functional (Sarmiento) bracing of humeral shaft fractures. J Shoulder Elbow Surg 2002;11(2):143-50. Crossref

46. Matsunaga FT, Tamaoki MJ, Matsumoto MH, Netto NA, Faloppa F, Belloti JC. Minimally invasive osteosynthesis with a bridge plate versusa functional brace for humeral shaft fractures: a randomized controlled trial. J Bone Joint Surg Am 2017;99(7):583-92. Crossref

47. Ali E, Griffiths D, Obi N, Tytherleigh-Strong G, Van Rensburg L. Nonoperative treatment of humeral shaft fractures revisited. J Shoulder Elbow Surg 2015;24(2):210-4. Crossref

48. Rutgers M, Ring D. Treatment of diaphyseal fractures of the humerus using a functional brace. J Orthop Trauma 2006;20(9):597-601. Crossref

49. Toivanen JA, Nieminen J, Laine HJ, Honkonen SE, Järvinen MJ. Functional treatment of closed humeral shaft fractures. Int Orthop 2005;29(1):10-3. Crossref

50. Pehlivan $\mathrm{O}$. Functional treatment of the distal third humeral shaft fractures. Arch Orthop Trauma Surg 2002;122(7):3905. Crossref 
51. Ekholm R, Tidermark J, Törnkvist H, Adami J, Ponzer S. Outcome after closed functional treatment of humeral shaft fractures. J Orthop Trauma 2006;20(9):591-6. Crossref

52. Ring D, Chin K, Taghinia AH, Jupiter JB. Nonunion after functional brace treatment of diaphyseal humerus fractures. J Trauma 2007;62(5):1157-8. Crossref

53. Walker M, Palumbo B, Badman B, Brooks J, Van Gelderen J, Mighell M. Humeral shaft fractures: a review. J Shoulder Elbow Surg 2011;20(5):833-44. Crossref

54. Carroll EA, Schweppe M, Langfitt M, Miller AN, Halvorson JJ. Management of humeral shaft fractures. J Am Acad Orthop Surg 2012;20(7):423-33. Crossref
55. Shields E, Sundem L, Childs S, Maceroli M, Humphrey C, Ketz JP, Soles G, Gorczyca JT. The impact of residual angulation on patient reported functional outcome scores after nonoperative treatment for humeral shaft fractures. Injury 2015;47(4):914-8. Crossref

56. Fırat A, Deveci A, Güler F, Öçgüder A, Oğuz T, Bozkurt M. Evaluation of shoulder and elbow functions after treatment of humeral shaft fractures. Acta Orthop Traumatol Turc 2012;46(4):229-36. Crossref 